\title{
DEFINING EFFECTIVE ONLINE PEDAGOGY
}

\author{
John Steele, Grand Canyon University \\ Rick Holbeck, Grand Canyon University \\ Jean Mandernach, Grand Canyon University
}

\section{INTRODUCTION}

More than 5.8 million students are currently enrolled in online courses; this equates to one in four higher education students taking an online course (OLC, 2016). With so many students enrolled in online education, it is imperative that institutions examine factors that lead to their success. Average first-year student attrition is nearly 60\% (Parker, Perry, Chipperfield, Hamm, \& Pekrun, 2018), and as such, it is essential to identify underlying pedagogical best practices that lead to student learning, success, and satisfaction in the online classroom. While research offers a plethora of best practices for online instruction (Cantamessa, 2018; Pardino, Gleyzer, Javed, Reid-Hector, \& Heuer, 2018; Roddy et al., 2017; Wilson, 2018), many of these best practices offer conflicting or incomplete guidelines. Lacking is a set of universal pedagogical principles that underpin the range of various instructional strategies, techniques, and approaches. Rather, research points to the possibility that effective pedagogy in the online environment is dependent on key contextual factors that defy creation of generalizable best practices in online teaching. Recognizing the wide variability of online education, the underlying question may need to shift from, "What are the best practices in online teaching?" to, "What online instructional strategies are most effective within specific educational contexts?" This article summary provides a structure to think about instructional strategies, best practices, and online pedagogy as it applies to your teaching. We offer a brief discussion of key contextual factors that may influence the generalizability of the online teaching suggestions provided throughout this special issue. In addition, we offer reflective questions to guide your application of the instructional approaches discussed.

\section{EFFECTIVE PEDAGOGY}

Luscinski (2018) defines a best practice as "a method that has been deemed more effective than other alternatives due to the positive outcome produced. A best practice is a technique or methodology that has been shown by experience and/or research to lead to a desired result" (p. 22). In online education there is considerable discussion of "best practices of online teaching;" however, what is coined "best practice" in the pedagogical literature differs as a function of disciplinary content, education level (bachelors, masters, and doctoral), curriculum, and instructional style. As such, it is possible that there simply is no "best practice;" thus, continued research to identify this non-existent instructional entity may distract from our ability to truly advance online pedagogy.

Serdyukov (2015) argues that we lack an effective theory or practice of pedagogy for the online classroom. Pedagogy includes virtually any strategy that enhances the learning experience (including instructional strategies, interaction with technology, vehicles for content delivery, etc.), and emphasizes the context and interactions of the teaching and learning dynamic. With all of these variables in place, instructors need to ask the following questions:

1. If a "best practice" exists, should it not be applicable across various domains to inform pedagogy?

2. If an online teaching and learning "best practice" or pedagogy is influenced by the learning environment itself (i.e., the learning management system and/or associated educational technologies), is it simply an instructional strategy?

To advance online teaching research, it is imperative to differentiate between instructional strategies, "best practices," and effective pedagogy.

\section{CHALLENGES IN DEFINING BEST PRACTICES}

Education Level (undergraduate, masters, doctoral)

Online courses are offered at all levels of higher education (undergraduate, masters, and 
doctoral). While some considerations are relevant to all of these levels (and may be considered a best practice), others may be specific to the course level, one of which is the technology readiness or selfefficacy of the students and faculty members. In addition, all three levels of education are designed to be instructed using different levels of Bloom's Taxonomy. Fish (2017) notes how Bloom's Taxonomy is a foundational framework for what an instructor can expect from a student at the various levels of education. Most instructors for undergraduate classes focus on the lower level of Bloom's Taxonomy (i.e., remembering and understanding) with activities such as multiple-choice questions, which tend to be more appropriate for this level (Fish, 2017). Thus, good pedagogy at the beginning undergraduate level may look different than at the graduate and doctoral levels because the focus may be more on recall, memorization, and explanation. In keeping with Bloom's taxonomy, graduate instruction tends to focus more on the middle of the framework with analyzing and evaluating content, which may require different technologies, techniques, and instructional strategies than undergraduate courses, while the doctoral level of instruction is primarily on analysis, evaluation, and creation. Because of the inherent differences in undergraduate, graduate, and doctoral programs, it makes sense that they may require different instructional strategies and tools.

In addition to the different levels of students, instructors may need to treat students at the beginning of a program differently than those who are further along in their program. Fish (2017) found that academic maturity was a significant aspect of why upperclassman typically perform much better than freshman. Furthermore, Toppin and Chitsonga (2016) determined that a student's academic maturity plays an important role in their performance and critical thinking, which was found to grow over time. Thus, if instructors can support students toward persistence it will eventually improve their academic performance. This brings up more questions when considering the use of various teaching strategies to implement in the online classroom:

1. What was the course level in which the strategy was effective?

2. How might the course level influence the value of the chosen strategy?
3. To what extent do you think this strategy would be effective with the courses you are teaching?

These questions would also all serve as excellent foundational questions for future research in this area.

\section{SOCIAL AND TEACHING PRESENCE}

One way to help students connect to the instructor is by increasing or including instructor presence in the online classroom. Kennette and Redd (2015) found that student learning outcomes in the online modality as compared to the traditional environment rely on the instructor creating a strong sense of teacher presence and social presence. In addition, Dalton (2018) found that the relationship the instructor makes with students is crucial to their achievement. First-year students who are new to college and may lack confidence need more immediate feedback or reinforcement. Because of this, a strong teaching and social presence can mediate academic immaturity and make first-year students feel more comfortable (Wilson \& Gore, 2013).

The importance of instructor presence is well-known in research into online education. Instructor presence can be defined as "how an instructor establishes his or her presence in an online environment can have important implications for the students' overall learning experience" (Richardson, Besser, Koehler, Lim, \& Strait, 2019, p. 82). Dalton (2018) went as far as to credit the instructor as being the most important determinant of student achievement in the online environment. Conversely, to what level does the need for more instructor presence vary? First-year undergraduate students (freshmen) may be much higher maintenance requiring a more involved and engaging presence by the instructor. While the presence of the instructor cannot be denied, to what degree and the way the instructor displays this presence may vary based on other various factors including LMS, content, student year, and student level. When considering the use of various instructional strategies to implement that increase presence, it brings to light the following questions:

1. What is the goal of increasing presence (connection with students, engagement, and so forth)? 
2. How does the age of my students impact the implementation of the strategy?

3. How far along are the students into their program?

4. What benefits do you want students to have from the addition of presence?

\section{DISCIPLINARY CONTENT AREA}

The disciplinary content area of a course can impact the instructional delivery strategy. However, so can instructor presence, different instructional strategies, and different technology inclusion. Studies have shown that students appreciate a choice in the way that they can receive the content (Lee, Pate, \& Cozart 2015; Mandernach, Robertson $\&$ Steele, 2018). Some content areas such as the hard sciences or mathematics may require more homework and/or practice problems, while other content areas may require different types of faculty engagement. For example, it may be more meaningful for instructors in the hard sciences to incorporate technologies or videos that can help students master difficult concepts that may be more abstract or needed with labs. Britt (2015) found that regardless of the subject area, students need to be engaged in meaningful ways. When considering the use of various teaching strategies you want to implement based on disciplinary course content, it is important to consider the subject matter in the class. Most important in this area:

1. Does the instructional strategy help students understand the content better?

2. Will the instructional strategy support additional student engagement in the content?

3. Can the instructional strategy provide students with a different perspective about the content?

\section{TECHNOLOGY INCLUSION}

One study by $\mathrm{Ng}$ (2018) showed a $42 \%$ increase in retention in a chemistry course by adding two technological elements to the curriculum. In addition, Fiorella, Stull, Kuhlmann, and Mayer (2018) found that the social and cognitive cues that the instructor gives throughout a video lecture can influence a student's learning, attention, and or engagement in video lectures. Another study by Fish (2017), found that instructors incorrectly believe that anywhere that informational technology is implemented in the online classroom equates to student learning. Thus, an instructor's technology readiness or technology self-efficacy may impact the quality of technology inclusion consequently impacting student achievement. Technologies need to be incorporated based on need and implemented using some sort of evaluation tool to ensure that the technology serves an important purpose. When incorporating technology into the online classroom you want to consider the following questions:

1. Is the technology easy access?

2. Is the technology easy to use?

3. How will the addition of technology benefit student learning?

\section{CONCLUSION}

While there is a lot written about best practices and good instructional techniques in online education, there is still confusion as to a single pedagogical theory. Serdyukov (2015) described the need for this theory, provided multiple areas to consider, and created a model called E-pedagogy, which can be used to create a theory of online pedagogy. Experience has shown that there are many variables to consider when thinking about pedagogy in online learning. It seems that the deeper this is looked at, the more questions that arise. Future research must be done in this to create a singular theory. The questions raised throughout this article are important in learning more about this phenomenon. Best practices may not be as generalizable as they appear. 


\section{References}

Baghdadi, Z. (2011). Best practices in online education: Online instructors, courses, and administrators. Turkish Online Journal of Distance Education, 12(3), 109-117.

Britt, M. (2015). How to better engage online students with online strategies. College Student Journal, 3, 399-404.

Cantamessa, P. (2018). Nurse faculty knowledge of best practices in online pedagogy. Journal for Leadership and Instruction, 17(1), 8-12.

Dalton, M. H. (2018). Online programs in higher education: Strategies for developing quality courses. FOCUS on Colleges, Universities \& Schools, 12(1), 1-8.

Fish, L. A. (2017). The value of multiple choice questions in evaluating operations management learning through online homework versus in-class performance. Business Education Innovation Journal, 9(2), 103-109.

Fiorella, L., Stull, A. T., Kuhlmann, S., \& Mayer, R. E. (2018). Instructor presence in video lectures: The role of dynamic drawings, eye contact, and instructor visibility. Journal of Educational Psychology, 111(7), 1162-1171. doi-org.lopes.idm. oclc.org/10.1037/edu0000325.supp

Kennette, L. N., \& Redd, B. R. (2015). Instructor presence helps bridge the gap between online and on-campus learning. College Quarterly, 18(4).

Lee, E. E., Pate, J. J., \& Cozart, D. D. (2015). Autonomy support for online students. Techtrends: Linking Research \& Practice to Improve Learning, 59(4), 54-61.

Luscinski, A. (2018). Best practices in adult online learning. Dissertation Abstracts International, Section A: Humanities and Social Sciences.

Mandernach, B, J., Robertson, S. N. \& Steele, J.P. (2018). Beyond content: The value of instructor-student connections in the online classroom. Journal of Scholarship of Teaching and Learning, 18(4), 12-17. Retrieved from https://scholarworks. iu.edu/journals/index.php/josotl/article/view/23430

$\mathrm{Ng}$, K. (2018). Implementation of new communication tools to an online chemistry course. Journal of Educators Online, 15(1).

OLC. (2016, February 26). Report: One in four students enrolled in online courses. Retrieved from https:// onlinelearningconsortium.org/news_item/report-one-fourstudents-enrolled-online-courses/.

Pardino, A., Gleyzer, I., Javed, I., Reid-Hector, J., \& Heuer, A. (2018). The best pedagogical practices in graduate online learning: A systematic review. Creative Education, 7, 1123.
Parker, P. C., Perry, R. P., Chipperfield, J. G., Hamm, J. M., \& Pekrun, R. (2018). An attribution-based motivation treatment for low control students who are bored in online learning environments. Motivation Science, 4(2), 177-184. doi:10.1037/ mot0000081

Richardson, J. C., Besser, E., Koehler, A., Lim, J., \& Strait, M. (2016). Instructors' perceptions of instructor presence in online learning environments. International Review of Research in Open and Distributed Learning, 17(4), 82-104.

Serdyukov, P. (2015). Does online education need a special pedagogy? Journal of Computing and Information Technology, 23(1), 61-74. doi: 10.2498/cit.1002511.

Toppin, I. N., \& Chitsonga, S. (2016). Critical thinking skills and academic maturity: Emerging results from a five-year Quality Enhancement Plan (QEP) study. Journal of Inquiry and Action in Education, 7(2), 81-93.

Roddy, C, Amiet, D. L., Chung, J., Holt, C., Shaw, L., McKenzie, S., . . Mundy, M. E. (2017). Applying best practice in online learning, teaching, and support to intensive online environments: An integrative review. Frontiers in Education, 2(2017). doi-org.lopes.idm.oclc.org/10.3389/ feduc.2017.00059/full

Wilson, S. D. (2018). Leading edge online classroom education: Incorporating best practices beyond technology. American Journal of Business Education, 11(3), 41-48.

Wilson, S., \& Gore, J. (2013). An attachment model of university connectedness. The Journal of Experimental Education, 81(2), 178-198. 


\section{EMPIRICAL ARTICLES}

